\title{
Local Utilization of NGO Presence in Changing Discources of Education in Rural Malawi
}

\author{
Thomas McNamara
}

University of Melbourne, State of Victoria, Australia

\section{Doi:10.5901/mjss.2013.v4n7p47}

\begin{abstract}
The paper examines the utilization of NGOs in changing conceptions over what makes a person educated and the advantages and liabilities that presenting one's-self as educated provides among Malawian small farmers. Through an ethnographic account it will be demonstrated that locally embedded actors incorporate the presence of a variety of NGOs in their education related negotiations and meaning making. It is argued that the presence of NGOs provides opportunities for many of the less enfranchised to challenge the notion (often presented by rural Malawian elites) that only those who go to schools are educated. Such claims assist people to claim resources that are either divided among the community or family. Nevertheless, not all poor are in a position to make such claims, for example, female members of poor male-headed households.
\end{abstract}

Keywords: NGO Presence, Local Utilization, Self-presentation, Education as contested, Malawi

\section{Introduction}

This paper examines the utilization of NGOs in changing local conceptions over what makes a person educated and the advantages and liabilities that presenting one's-self as educated provides. It argues that NGO presence often incentivizes an individual to claim to be educated, and that, while NGOs are utilized by the disenfranchised in intercommunity contests over the meaning of education, not all poor people are in a position to make these claims, especially in intra-family negotiations. This paper focuses education as 'extralocal' knowledge, perceived as separate from local wisdom (Levinson \& Holland 1996).

The arguments that this paper presents are based on 11 months fieldwork in Northern Malawi, observing the utilization of three NGOs and a western funded and staffed CBO (which is undergoing NGO accreditation) by locals in fishing and farming villages. This fieldwork combined participant observation with interviews in English and chiTambuka, the northern Malawian lingwa franca. The focus is on neither the NGOs themselves nor the Malawian education system, but on how local actors use the presence of the NGOs to re-negotiate the meaning of education and the advantages this provides.

This paper will briefly summarize the Malawian schooling system and the educational options in the rural north, noting the absence of many opportunities that typically incentivize education. It will then focus on the symbolic claim of 'being educated' and the social and economic advantages the community and NGOs give to those they see as educated.

The paper examines the discursive contest over what constitutes education in the village consciousness. It explores the idea that years of schooling and quality (or cost) of school are the only determinants of level of education, a narrative typically presented by the monetary elite. This is compared to the aspirational poor's claim that the presence of an NGO can be utilized to create an equivalent educational status through non-formal classes and personal associations. 
The paper concludes by showing how the utilization of NGOs in education related status claims is embedded in the differing relationships between the NGOs and the community. It will posit that a greater acceptance of dominant community discourse by Mbwezi (pseudonym), the largest NGO in the area, assists disenfranchised male farmers in their intra-community claims but simultaneously allows them to turn Mbwezi's library into a masculinized space. This is juxtaposed against Place of Learning (pseudonym), the western directed $\mathrm{CBO}$, where an intolerance of local gendered hierarchies, along with a more general friction between the $\mathrm{CBO}$ and the community, has resulted in only women and children studying in their library. The paper shows that while Mbwezi's library provides men who read there with educational symbolic capital, Place of Learning does not do the same for women. This capital is utilized in an educated partner's claims on family resources. In exploring this, the paper demonstrates that a NGOs presence influences 'education', but that this is guided by the community and relates to the power dynamics and inequalities there-in.

\section{Background Information on Education in Malawi}

The Malawian Schooling system trades-off the quality of education for availability (Chisamya et al 2012). In 1994 the Government of Malawi (GoM) introduced a Free Primary Education (FPE) policy raising primary student numbers from 1.9 to 2.9 million students nationally (Rose 2003). This rapid expansion in coverage reduced the quality of education, demonstrated by a $70 \%$ primary student drop-out rate, large numbers of under-qualified teachers and poor educational outcomes (Kadzamira \& Rose 2003, Mtika \& Gates 2010, Bisika et al 2009 \& Jere 2012 pg.756).

Primary education is expensive for both the government and families. The GoM spends $25 \%$ of recurrent funds on education (Rose 2005 \& Chisamya et al 2012). Poor households spend approximately 6\% of their total income per child in school on school related expenses, a total cost increased by the additional enrolments FPE encourages (Kadzamira \& Rose pg.506). These costs are compounded by inadequate post primary options. Malawi has one of the lowest participation rates in secondary schooling Africa, with net attendance under 10\% (Chimomobo 2005 pg.168-171). Numbers initially increased after FPE as secondary education was seen as necessity for obtaining employment; however they have been declining since 2000 due to skepticism about the Nation's education system (Rose 2005 \& Chimombo 2009 pg.173).

Students are selected to secondary schools on merit, with the highest ranked going to national schools, the next best going to district boarding schools and the poorest (though still a minority) going to Community Day Secondary Schools (CDSSs) (Kamwendo 2010). There 1106 registered Secondary Schools in Malawi; 171 public, 627 CDSSs and 318 Private. In 2000 only one in three standard eight students found a place only a public school and urban Malawians were more than ten times as likely as those from rural areas (Chimombo 2009).

The CDSS system is the only option for the majority of people in the rural north. Communities construct CDSSs in their area and the government provides teachers and learning materials (Kayuni 2010). The quality of education offered there is very low, with only $7 \%$ of teachers qualified and a teacher to student ratio of well over 1:100, in 1999 only 5\% of boys and 1\% of girls from CDSS's passed their exams (Chimomobo 2009 \& Bray 2000, Mtika \& Gates 2010, Kayuni 2010 \& Kadzamira \& Rose 2003). Private schools offer an educational alternative and provide an option to students who have failed in government or CDSSs schools; however they are well outside the financial resources of most rural residents (Chimomobo 2009).

NGOs and donors focus on provision schooling in Malawi to girls and girls will soon out number boys in the Malawian primary system (Stambach 1998, Chimomobo 2009 \& Kadzamira \& Rose 2003). This not been accompanied by deeper transformations to a system of gender relations that impedes female education. Care-work is feminized and post-menstrual girls have their rights to schooling questioned through sexualized bullying and impregnation (Chisamaya et al 2012, Bisika et al 2009 \& Kadzamira \& Rose 2003). Few girls complete primary school and they are still under-represented at high school (Kamwendo 2010, Chimomobo 2009 \& Davidson \& Kanyuka 1990) 


\section{Schooling and Eduction in Northern Malawi}

The area I studied has good primary education, but inadequate secondary schooling. There is near universal primary coverage along this section of the Northern Malawian Lakeside and the wealthy utilize the local system, demonstrating confidence in it. However the small genuinely wealthy class (NGO workers, highly skilled civil and health workers and returned international miners) send their children to private high schools in Lilongwe and Mzuzu. The socially connected, ambitious and financially stable, (still a very small portion of the rural North), attempt to have their children receive hardship bursaries to Catholic Schools in Mzuzu. Admittance requires the financial flexibility to pay for transport to Mzuzu and to lose an economically productive household member for long periods.

The local high school options comprised a low fee private school and a CDSS. At 3000mk a semester, the private school was one and a half times the cost of the public option and most felt it provided a slightly superior though still insufficient education. The CDSS was a particularly poor school, no one from there has ever gone on to university and it has one of the worst pass rates in the country. One of the students observed that '[t] the person who teaches form 4 hasn't finished form 4 themselves' and rumors that the staff slept with female students were rife. The CDSS attempts to associate itself with Mbwezi, hoping to use the NGO's popularity to re-enforce its local legitimacy. A teacher told me '[t] Mbwezi knows that it would not exist without the school and the school teachers, when Mbwezi came no one wanted them but the teachers realized their vision and decided to help'. To cement this association, students are often used for volunteer labor by Mbwezi.

Mbwezi and Place of Learning provide non-school based adult education. Place of Learning ran English lessons once a week for a local women's group and other classes depending upon the international volunteers available at the time. These are locally considered inferior to conventional schooling (Bloch \& Varus 1998 \& Rose 2009). Mbwezi ran classes from their hall and allowed smaller NGOs to do so. When these NGOs were teaching, Mbwezi staff would come in, introduce the speaker, make jokes and stress the importance of the course, linking the lesson to Mbwezi in the minds of recipients. Some claimed that Mbwezi's classes constituted an education, an informant told me that '[t] a lot of people learn from Mbwezi instead of going to school, because they don't have money for fees'. The level to which Mbwezi provided classes could enhance a person's claim to be 'educated' and the reasons Place of Learning did not are discussed in this paper.

\section{Incentives for Education in Norther Malawi}

Secondary schooling is seen as the minimum for entering the job market in Malawi, however this job market does not exist in the rural North (Kadzamira \& Rose 2003). The jobs that required an education in the over ten thousand person region I studied were: NGO jobs, around twenty of which would have required a Malawi School Certificate (MSC-finishing high school), five jobs at the hospital that would have necessitated tertiary education (and were not filled by locals) another ten where a Malawian Junior School Certificate (MJSCfinishing the first two years of high school) would have been preferable and a collection of teachers (under 50), some of whom had less than a MSC. MSC holders were also looked upon favorably when these employers needed short term workers. People told me that ' $[\mathrm{t}]$ people who finish form 4 [MSC] go out and find jobs where people who finish form 2 [MJSC] are just staying'. However, when questioned further, most acknowledged that there were many more people with MSC educations than jobs. Others claimed that an education made asking for money or gifts from the occasional tourist or seeking work in South Africa easier, though most of the best local English speakers had little schooling.

Despite disincentives to put children in school, including cost, lost labor and teachers impregnating students, rural northern Malawians use a variety of strategies to claim as good a position as possible in the formal schooling system and attempted to present themselves as 'educated' when able (Kadzamira \& Rose 
2003 \& Kishindo 2000). This paper posits that, even in environments where being educated provides few financial advantages, there is significant cultural capital attached to being educated (Levinson 1996 pg.218). For those studied, this capital involved the ability to claim NGO resources, and could be negotiated through an association with an NGO or other utilizations of NGO presence.

\section{The Social Claim of Being Educated}

The social claim of 'being educated' provides significant benefits to those in the developing world who do not receive material advantages through education. Education serves as a form of symbolic capital, assisting claims to superior statuses and positions in the household and community (Skinner \& Holland 1996 pg.274). What constitutes an 'educated person' is culturally specific, mediated by social interactions and local meanings (Rockwell 1996, Bartlett 2007 \& Vaveus 2002). Students and graduates produce, enforce and challenge notions of the 'educated person', as do the actions of NGO workers in rural Malawi (Condy 1998). Good relationships between schools and communities increase the local value of education, and if the schools are unpopular this value is often negotiated through other organizations, including NGOs (Chimomobo 2005 \& MacJessie-Mbewe 2004).

'Being educated' provides advantages including feeling entitled to express oneself in front of elders or community leaders and to be given the benefit of the doubt on issues like debts (Shaw 1996 Kishindo 2000 \& Bartlett 2007). Educated women have an enhanced ability to negotiate later marriage, refute sexual partners and critique gender roles (Vaveus 2002 \& Skinner \& Holland 1996).

\section{The Advantages of the Educated Person in Northern Malawi}

Among the small holders studied 'being educated' provided a collection of advantages, influencing how a person was perceived and their role in the community. Educated people were seen to live a good life, allowed ambition and listened to when decisions were made, especially those relating to development. People told me that "[tr] a person is referred to as educated if their problems are all finished, if they have a job and can find money and can help their family,'. This contrasted with the uneducated, who locals claim were poor because of their ignorance and who would not have food in their houses.

'Being educated' allowed a small-holder to search for jobs in the NGO and government sector, turning down fishing and farm work without appearing lazy. A respondent in a remote village explained that ' $\mathrm{t}$ ] Gunzan [a chief's son] has been to school. He has finished form 4 and worked [volunteered] at the hospital so he cannot work as a fisherman'. Further, an educated person could save rather than share their income, and wealth they obtained was attributed to their education. When the uneducated had money it was assumed to be a result of selfishness or witchcraft.

People claimed that the uneducated did not have the mentality to do anything other than '[t] just stay', while the educated were capable of assisting the region. Some believed educated individuals filled an emerging whole in village social structure, as local hierarchies diminished in the face of increasing materialism:

'[tr] in the old times everyone listen to the elders but now they don't respect them and that's why people go to school, people respect people who went to school because now everything you need to buy'.

There were liabilities associated with the claim to being educated, both for the claimant and for the community. Many educated people felt their meager savings were inflated in the minds of the community and they were often asked for significant assistance: ' $[\mathrm{t}$ ] if you make your money farming you can tell people if you want money go and farm... but if you are educated you just sit and the money comes to you'. Educated people claimed that they were unable to work as either a fisherman or farmer due to expectations that they 
achieve more than this. However others claimed they were unwilling to work, instead drinking and using their education to negotiate additional sexual partners.

\subsection{NGO Presence and the Advantages of the Educated Person in Northern Malawi}

The presence of NGOs in rural northern Malawi was involved in creating and incentivizing locals' claims to be 'educated'. NGO staff were seen to be educated and NGOs provided nearly all of the employment the educated aspired too. In some villages the only jobs other than fishing, hawking and farm work were provided by NGOs. NGOs were perceived to favor the educated in terms of sociability and resource provisioning. A person could both become 'educated' by volunteering with NGOs and prestigious types of volunteering (which 'the educated' were selected to do) provided material and cultural wealth to a volunteer.

Farmers modeled their understandings of an educated life on how they interpreted NGO staff member's presence (Rival 1996 pg.157). I was told that '[t] Juliet [a female staff member] lives like an mzungu (white person) because she has few children and a lot of education', associating this women's reproductive choices with her education and profession. Others observed that staff members did not farm or perform labor. Many people felt that NGO staff treated many locals poorly, but would mix socially with the educated. Sometimes these claims were made by those without an education, to pressure others to assist them, typically though it was 'the educated' that used the presence of NGOs to inspire and negotiate the advantages that education provided.

The intercommunity interaction between the NGOs and the concept of 'education' that was most beneficial to an individual was volunteering. Volunteers were typically selected by either the chief or NGO staff because they were educated, with the staff or chief solidifying the volunteer's self-depiction as educated by doing this. These volunteers would then attend training for which they would often receive 'appearance fees' and they were granted special status in their community by their chief. They would likely become recipients when the chief had NGO provided resources (for example seeds) to give out. A Chief admitted to me that his volunteers misappropriate resources from the NGOs they assist, but feels this is a privilege of their educational status and a necessary compromise between his village and those within it who are capable of bringing development:

'[t] if widows and orphans come to me and say we are not receiving I will tell them that I sent an educated person to Mbwezi, if they do not want that person to help them they can go to Mbwezi themselves, but they will be unable to because they haven't learnt'

The advantages of being educated are determined by local actors' interactions with the presence of the NGOs, rather than the actions of the NGOs themselves. Chiefs influence how education is viewed in their village; many of the newer chiefs in northern Malawi are well educated and valued education (Chimomobo 2005). Similarly, in villages where the local oligarchs are educated, 'education' often provides greater prestige than in those where the wealthy are unschooled.

This can be demonstrated by considering the case of Barya and Revor (pseudonyms), two small villages adjacent to each other along the lakeshore. Revor's wealthiest man has no education and is not investing in his children's or others in his familiy's learning. He states; ' $[\mathrm{t}$ ] there are two groups in Revor, group 1 goes to school and group 2 doesn't go to school, group 2 can cut down trees but group 1 cannot.' His attitude is mirrored by, and models for, many in the village, who are embittered towards schooling. In contrast in Barya the wealthiest man is paying for his younger brother's tertiary education (a short computer course in Mzuzu), with the aim of sending others from his family and community to external schools and eventually generating long term tertiary enrolment.

These differing attitudes to education are influenced by conflicts in the community between the chiefs and oligarchs and the utilization of NGOs in these. The chief of Revor is well educated and leverages the link between education and development to solidify his legitimacy as village leader. For this reason he rarely 
sends other 'educated' people to volunteer, denying the symbolic capital that 'education' could provide another family in the village. He also links education and development when asking people to partake in unpaid agricultural work for Mbwezi, claiming that this tedious labor allows the uneducated to contribute to the development of the village. In contrast, Barya's oligarch is the chief's son, and his brother (whose education he is paying for), does significant volunteering with NGOs in the area. By the chief and his son choosing to value this volunteering and demark it as a sign of 'education' (a concept which they also advocate value for) they are able to differentiate the younger brother from the rest of the village, justifying the significant portion of the villages resources that are being spent on him.

\section{Claims to be Educated in Northern Malawi}

Who it is that can claim to be educated, accessing the social, cultural and economic resources of education, is locally negotiated through culture, the community and local institutions (Bartlett 2007, Kadzamira \& Rose 2003). Where I studied, who is 'educated' represents a contest between local elites (who use their wealth to monopolize dominant understandings of education) and entrepreneurial poor, who use a variety of strategies, mainly centered on exploiting NGO presence, to claim 'educated' status as they cannot afford expensive school options.

The wealthiest and poorest residents both believed that being educated necessitated either expensive private schooling or a tertiary qualification, and that as such, few locals are educated. My richest respondent described a MSC as '[t] nothing' and a MJSC as '[t] less than nothing'. He had put all his children through private education and some form of tertiary training. His opinion was shared by many of the village elite, including NGO workers who stressed that some form of post-secondary certificate was necessary for their employment. Some used their schooling to differentiate themselves from equally rich but uncultured locals. The aforementioned respondent explained that there were others in the village who were wealthy enough to live chalo chazungu (a white person's life), like he did, but lacked the education. Those with no formal education also claimed that being educated required more than a MSC, meaning that almost no one in Usisya was educated. They were quick to point out that a local with a MSC was no more able to find a job than they were.

The elites and the ultra-marginalized had a common goal of limiting 'educated' status to a tiny minority. The elites would comprise this minority and the uneducated would be excluded from it regardless of its size. A strict definition of 'educated' assisted both groups' claims to NGO resources, as the provisioning of NGO materials by either chiefs or NGO workers was typically a compromise between entitlements centered on education (to those who would use them efficiently), and need (to the poorest members of the community). A wealthy member of the community would make their case for these resources based on being the most educated person in the area. The most disadvantaged needed there to be as little value as possible in a MSC or MJSC education so that they could claim these resources based on their greater need, without concerns others might be 'educated' enough to utilize them more effectively.

Most Usisyans felt a person was educated if they had a MSC and possibly educated if they had a MJSC. Those with a MSC stated that a MJSC merely taught students to write, where a MSC provided the intangible quality of living well, allowing them to respectfully disagree with their elders and making them authorities on development. Many with a MJSC counter that a person with a MSC who lived in the village was rarely better off than they were. Teco, a rich bar owner, explained ' $\mathrm{t}$ ] If you just stay in the village then form 2 and form 4 are equal because the education has not assisted you'. In the further out villages were MSCs were rare a MJSC made someone educated.

Employment or the ability to speak English provided a person with education related symbolic capital. This was particularly prevalent among people with a MJSC or less, and its validity was fiercely contested by those with more formal schooling but less post school success. Many (especially those with a form 2 or less) claimed that anyone with a good job or international experience was educated. Patrick, a local nurse who had 
failed his MSC told me '[t] I am educated because I have this job'. Speaking English (or better still, being seen reading English), was a common strategy for claiming educational equivalence to someone with a MSC. Teco, when explaining why he did not provide his child with post-primary education told another wealthy local:

" $[t]$ If they can speak chazungu by standard 8 [the end of primary school] they are more educated than you and why would they want to learn it again till form 4'.

As NGOs represented physical sites of education and modernity, people utilized their presence in claims to being educated. Locals would manufacture a special friendship with NGO staff, one repeatedly told me he went to the most senior development worker in the area's house to '[t] discuss development and read the political newspapers', evoking the language of development and its link to education. Others attended courses either provided by NGOs or at Mbewzi's community center.

The understandings of education negotiated built on existing relationships within the village. For example, a class run a popular NGO worker in the village on 'business', would have a greater educational status than one run by a female staff member on sexual health. Further, the relative popularity of the NGOs was crucial in determining their ability to be perceived to provide 'education'. This popularity was related to their perceived respect for community 'values', limiting the potential to educational claims from the most disenfranchised; specifically women and children.

\section{Libraries and the Role of the Relationship Between NGOs and Community in Detetmining Educational Value}

Both Mbwezi and Place of Learning have large libraries, each with approximately four thousand books, and five hundred newspapers and magazines. Where the majority of respondents agreed that going to Mbwezi's library was a sign that a person was educated, they did not feel that way about Place of Learning. This was because Mbwezi's library was more accommodating of local cultural norms, which encouraged locals to value it and utilize its presence in their claims to education. However, this also incentivized and enabled men to dominate the space, gifting them the status of 'educated' in their interfamily negotiations.

Mbwezi's library has a table of newspapers, a selection of novels and a collection of educational books, dictionaries and thesauruses. The newspapers were read by adult men, some were illiterate, but enjoyed the social aspects of library attendance and others' perceptions that they were reading the newspaper in English. There were often late primary and early high school students present, almost exclusively male, who skim books that looked educational, typically thesauri and dictionaries.

Being at Mbwezi's library could be utilized as a sign that you were educated or a way to become educated. Many claimed that reading in the library showed you were an educated person because you were able to read and valued learning. A fisherman explained to me; '[tr] a person who goes to Mbwezi library is educated because they are living differently to everyone who is just staying'. Patrick, the health worker mentioned earlier, would falsely claim that he went to the library. Some people felt that a person could achieve equivalent education at Mbwezi's library to school, one specified that readers there would ' $[\mathrm{t}]$ learn things and will be more educated than those who study'. Others protested that people just went to Mbwezi to read novels, or look at pictures, and that this did not constitute education, which could only be achieved through the schooling (that they had typically received and many of those reading at Mbwezi had not). However, their opinions were rebutted by older males, who read at Mbwezi, had little formal schooling and desired to be perceived as educated.

The success of Mbewzi in providing 'education' necessitated that its internal power dynamics reflected dominant age and gender discourses within the general community (Trujillio 1996). Elder males would take the seats and reading materials of the younger and dominated the newspaper reading table, and the staff 
would unofficially tolerate their conversation. Chiefs and other village dignities were given special privileges and attention by the staff. Women would utilize the library when it was empty or take a small table at the back when only schoolboys were around. They excluded themselves from the library due to a fear that those who went there would be subject to rumors that they were sleeping with (or attempting to sleep with) either an Mbwezi staff member or an educated man. Many felt that where a man could go to the library and pretend to read, a woman doing the same would be laughed at. Women had domestic tasks, including child rearing and, as this library was prestigious, they did not want to take a baby there that could cry and upset others.

This acquiescence to 'local customs' was not found at Place of Learning's Library, where women and high school students of both genders would talk and read educational books. There were also primary school aged children in the library, exticed by the international volunteers who lavished attention upon them. Elder men refused to go to Place of Learning's library as they felt disrespected by the organization which failed to acknowledge their seniority. One claimed' $[\mathrm{t}]$ the people who have been to school here are also the people who like to drink beer, there might be some people who think drinking is bad, but they haven't been to school', a reference to the perception that the non-drinking staff and the (typically female) international volunteers judged and isolated themselves from local males. Some would sit for hours reading and rereading the same small selection of Jehovah's Witness magazines but would claim that, as older men, they could not be seen at the library. One well educated man volunteered at Place of Learning but would read at Mbwezi's library.

Place of Learning's rejection of local power dynamics meant women and children could improve their reading and writing at the library unaccosted, but that it could not provide the symbolic capital of education. Women and children felt welcome due to the feminized presence and the fact that men were largely absent. Women went in groups to practice reading and one explained to be ' $[\mathrm{t}]$ men don't go to the library because they cannot read and are too shy/ashamed to learn'. Place of Learning had a positive effect on the reading levels of the poorest local children. These students often received noticeably better grades in English language and literacy than in their other subjects, as they would go to the library when turned away from school for not wearing a uniform.

Men were adamant that women and children were not gaining education at Place of Learning. On the subject of the women's reading group I was told '[t]people don't go there to learn, they are just reading and if they can't read are just staying', and regarding children reading there

"[t]they teach children to read... and now children just want to go to Place of Learning, they skip school because they think it is better at Place of Learning, it is better they go to school'.

Place of Learning's library provided better educational outcomes to a more disenfranchised group; however, it was not able to provide the cultural capital of 'education'. In contrast Mbwezi's ability to provide education through its library was intimately tied to the respect for dominant local discourses. While Mbwezi itself did not gender the library, by reflecting uncritically 'traditional' society they allowed their library to become valuable and to be appropriated by men. This gifted males easy access to 'education' to use in their intra-household negotiations.

\section{Education and Intra-Household Negotiations}

The educated have significant advantages in terms of intra-household resource negotiations, assisting them with reproductive choice and wealth allocation (Vaveus 2002 \& Rival 1996 pg.156). These negotiations takes place in the context of local gender norms, with Malawi women socialized to be subservient to male household heads; educated women are experiencing a slight improvement of intra-household gender relations (Chisamya et al 2012 pg.743 \& Ngwira 1988 pp.1-3). 
Where I studied men were able to use their greater educational status in intra-household wealth appropriation. This was, in part, due to many men's ability to present themselves as educated easily through library attendance or socializing with NGO staff. An NGO volunteer without a MSC invested significant family resources into his personal entrepreneurial activities. He explained to his wife and I that this was because '[e] I have an education, for me to work as a night watchman it is no good, but jobs here are few, maybe I can get work [in town] as a carpenter'. Many men (often with a MJSC or less) would use an educational claim that tied them to an NGO or NGO worker to cement their dominance over the household finances, which their wife '[t] does [didn't] have the mind to understand,' or went to the library to improve their education while their wife performed farm work.

The other aspect of interfamily negotiation where the influence of the NGOs' libraries was apparent was school fees. Parents' decision to send child to school is influenced by their assessment of the child's intellect, the costs involved in education and need for child's labor and that students negotiate their attendance based on intra-family power dynamics (Shaw 1996 \& Davidson 1993).

NGO presence in across the Malawian lakeshore a priori appeared to incentivize spending money on a daughter's school fees at the expense of a son's. Local female NGO workers were known for giving money to their parents. Girls explained to me '[e] Tovia is helpful to her family but many men can't provide basic needs for their families so they envy her'. It was widely acknowledged that both NGOs and government services would employ women over men because they were '[t] looking for gender'. The small number of females with a MSC were either full time employed or consistently offered short term contracts and prestigious volunteering opportunities. Exceptionally canny locals quietly admitted that their preference their daughter's schooling over their son's to carry favor with NGOs and in the knowledge that white volunteers were more likely to 'sponsor' a female child.

Despite this, high school aged boys were much more able than girls to use Mbwezi's library to claim a family's limited resources for their school fees. Most families that sent children to high school selected one or two to go and would select their smartest, best behaved or most dedicated. Boys at Mbwezi's library admitted that showing intelligence and ambition to their parents was part of the reason they studied there. Girls felt unwelcome at there and they did not gain the same interfamily credit from reading at Place of Learning. Some parents explicitly preferenced a child who studied at Mbwezi when determining who to send to school and I knew of one case where a son used his time at Mbwezi to negotiate private school attendance, while his sisters were denied high school education.

\section{Conclusion}

The presence of various NGOs opened up new spaces and strategies for claims to 'education', as well as adding to the incentives to make these claims. Negotiations as to how NGOs affected understandings of education were embedded in, reflected and were limited by local prejudices. They provided enough latitude for entrepreneurial locals to contest the dominant understanding of education as measured in years and cost of school. However, the interplay between NGO presence, 'local culture' and education diminished women's intra-household bargaining position.

The perception of education was altered (and its status was raised) through local utilization of the presence of NGOs. Chiefs provisioned NGO resources to 'the educated', individuals sought exposure though volunteering and locals attempted to mirror the lives of educated NGO staff.

NGO presence was utilized in individuals' claims that they were educated. Some befriended NGO workers, others attended courses and others volunteered, attempting to show that they were worthy of the resources being educated provided. These educational claims were contested as it was in the best interests of the most and least powerful in Usisya for educational status to be exclusive and rare.

The role of NGO presence in renegotiating claims to education was tempered by the relationships between the communities and NGOs and, as such, exacerbated intra-family inequality. Mbwezi were popular 
at least in part because of their identification with 'traditional culture,' while Place of Learning was perceived to lack respect for community values including gender norms. The association between Mbwezi and 'the local' both allowed and incentivized male capture of education related symbolic capital, though their monopolization of Mbwezi's library. Men then used their status as the educated member of the family in intrahousehold negotiations.

This paper has shown how NGOs were used in changes to the local understandings that surrounded education. It has shown that the changes were not externally driven, but were negotiated, co-created and subverted by the circumstances of the village and the ambitions of the actors therein. In this way education was reshaped and appropriated through locals' utilization of the presence of NGOs, a process that both challenged and was limited by local power dynamics. NGO workers and education professional should take note of these factors when considering how their own presence interacts with local discourses to create meanings for education and power relations that go with this.

\section{References}

Bartlett, L (2007) Human Capital or human Connections? The Cultural Meanings of Education in Brazil Teachers College Record 109:7 pp.1613-1636

Bisika, T, Ntata, P \& Konyani, S (2009) Gender violence and education in Malawi: a study of violence against girls as an obstruction to universal primary school education Journal of Gender Studies 18:3 pp.287-294

Bloch, M \& Varus, N (1998) Preface in (eds) Bloch, M, Beoku-Betts, J A \& Tabachnick (1998) Women and Education in Sub-Saharan Africa: Power, Opportunities and Constraints Lynne Rienner Publishers pp.1-24

Chimomobo, J P G (2005) Quantity versus Quality in Education: case studies in Malawi International Review of Education 51 pp.155-172

Chimombo, J (2009) Changing Patterns of access to basic education in Malawi: a story of a mixed bag? Comparative Education 45:2 pp.297-312

Chisamya, G, DeJaeghere, J, Kendall, N \& Kahn, M A (2012) Gender and Education for All: Progress and problems in achieving gender equity International Journal of Educational Development 32 pp.743-755

Condy, A (1998) Improving the Quality of Teaching and Learning through Community Participation: Achievements, Limitations and Risks, Early Lessons from the Schooling Improvement Fund in Ghana Social Development Working Paper No.2 July

Davidson, J (1993) School Attainment and Gender: Attitudes of Kenyan and Malawian Parents Toward Educating Girls International Journal of Educational Development 13:4 pp.331-338

Davidson, J \& Kanyuka, M (1990) An ethnographic study of factors affecting the education of girls in Southern Malawi Ministry for Education and Culture \& US Agency for Internationl Development Chancellor College, University of Malawi $30^{\text {th }}$ October

Jere, C M (2012) Improving educational access of vulnerable children in high HIV prevalence communities of Malawi: The potential of open and flexible learning strategies International Journal of Educational Development 32 pp.756-763

Kadzamira, E \& Rose, P (2003) Can free primary education meet the needs of the poor?: evidence from Malawi International Journal of Educational Development 23 pp.501-516

Kamwendo, M (2010) A Comparison of students' achievement in private and conventional public secondary schools in Malawi from a gender perspective Research in Education 83 pp.17-25

Kayuni, H (2010) Chaos complexity theory and Education Policy: Lessons from Malawi's Community Day Secondary Schools Bulgarian Journal of Science and Education Policy 4:1 5-31

Kishindo, P (2000) Community Project Funding in Malawi under the Malawi Social Action Fund (MASAF) Demand Driven Approach: Potential for Perpetuating Imbalances in Development Journal of Social Development in Africa 15:1 pp.5-14

Levinson, B A (1996) Social Difference and Schooled Identity at a Mexican Secudaria in (eds) Levinson, B A, Foley, D E \& Holland, D C (1996) The Cultural Production of the Educated Person; Critical Ethnographies of Schooling and Local Practice State University of New York Press Albany New York pp.211-239

Levinson, B A \& Holland, D C (1996) The Cultural Production of the Education Person: An Introduction in (eds) Levinson, B A, Foley, D E \& Holland, D C (1996) The Cultural Prodcution of the Eductated Person; Critical Ethnographies of Schooling and Local Practice State University of New York Press Albany New York pp.1-56 
MacJessie-Mbewe, S (2004) Rural Communities-Education Relationship in Developing countries: The Case of Malawi International Education Journal 5:3 pp.308-330

Miller, C \& Tsoka, M (2012) Cash Transfers and Children's Education and Labour among Malawi's Poor Development Policy Review 30:4 pp.499-522

Mtika, P \& Gates, P (2010) Developing learner-centered education among secondary trainee teachers in Malawi: The dilemma of appropriation and application International Journal of Educational Development 30 pp.396-404

Ngwira, N (1988) Organization and management of agricultural services for small farmers in Malawi University of Malawi Centre for Social Research

Rival, L (1996) Formal Schooling and the Production of Modern Citizens in the Ecuadorian Amazon in (eds) Levinson, B A, Foley, D E \& Holland, D C (1996) The Cultural Production of the Educated Person; Critical Ethnographies of Schooling and Local Practice State University of New York Press Albany New York pp.153-169

Rockwell, E (1996) Keys to Appropriation: Rural Schooling in Mexico in (eds) Levinson, B A, Foley, D E \& Holland, D C (1996) The Cultural Production of the Educated Person; Critical Ethnographies of Schooling and Local Practice State University of New York Press Albany New York pp.93-118

Rose, P (2003) Community Participation in School Policy and Practice in Malawi: balancing local knowledge, national policies and international agency priorities Compare: A Journal of Comparative and International Education 33:1 pp.47-64

Rose, P (2005) Privatisation and decentralisaiton of schooling in Malawi: default or design? Compare: A Journal of Comparative and International Education 35:2 pp.153-165

Rose, P (2009) NGO provision of basic education: alternative or complementary service delivery to support access to the excluded? Compare: A Journal of Comparative and International Education 39:2 pp.219-233

Shaw, T A (1996) Taiwanese Schools against Themselves: School Culture Versus the Subjectivity of Youth in (eds) Levinson, B A, Foley, D E \& Holland, D C (1996) The Cultural Production of the Educated Person; Critical Ethnographies of Schooling and Local Practice State University of New York Press Albany New York pp.187-210

Skinner, D \& Holland, D (1996) Schools and the Cultural Production of the Educated Person in a Nepalese Hill Community in (eds) Levinson, B A, Foley, D E \& Holland, D C (1996) The Cultural Production of the Educated Person; Critical Ethnographies of Schooling and Local Practice State University of New York Press Albany New York pp.273-300

Stambach, A (1998) 'Education Is My Husband: " Marriage, Gender and Reproduciton in Northern Tanzania in (eds) Bloch, M, Beoku-Betts, J A \& Tabachnick (1998) Women and Education in Sub-Saharan Africa: Power, Opportunities and Constraints Lynne Rienner Publishers pp.185-200

Vaveus, F (2002) Making Distinctions: privatisation and the (un)educated girl on Mount Kilimanjaro, Tanzania International Journal of Educational Development 22 pp.527-547 
